\title{
THE INFLUENCE OF THE SELECTIVE LASER MELTING PROCESS PARAMETERS ON THE MICROSTRUCTURE OF NICKEL-BASED SINGLE CRYSTAL ALLOY
}

\author{
Kirill STARIKOV, Evgenii BORISOV, Igor POLOZOV, Anatoly POPOVICH \\ Peter the Great St. Petersburg Polytechnic University, St. Petersburg, Russia, \\ kirill.starikov@gmail.com
}

https://doi.org/10.37904/metal.2021.4234

\begin{abstract}
Currently, nickel heat-resistant single-crystal (SX) alloys of the second generation are the most popular in the production of gas turbine blades. Direct crystallization technology for manufacturing of SX turbine blades is associated with the inability to fully utilize the potential of the alloy. Such a limitation is caused by the formation of shrinkage micropores as well as limited geometrical complexity of part. Selective laser melting process can be utilized to overcome this problem. The influence of the selective laser melting process parameters on the microstructure of compact samples was investigated. Several sets of laser processing parameters were selected with the same value of volume energy density, hatch distance, but different scanning speed and laser power. The relationship between the laser bed fusion parameters and the width of gamma/gamma' - phases was determined.
\end{abstract}

Keywords: Selective laser melting, single crystal alloys, powder metallurgy, additive manufacturing

\section{INTRODUCTION}

The modern development of the selective laser melting (SLM) technology is primarily moving in two directions: the study of new alloys and possible new applications of additive manufacturing [1-3], and investigation of the influence of various SLM process parameters on density, structure and, as a consequence, the properties of the resulting products $[4,5]$.

Nowadays, additive technologies are integrated to a low degree into existing technological chains, which is due to the relative scientific and technical novelty, the lack of standards and a poor understanding of their application possibilities. However, despite the problems listed above, the technology we are considering has a number of undeniable advantages over traditional methods of processing materials. The most obvious is the almost complete absence of restrictions in the topology of the resulting products, which makes it possible to optimize the existing and currently used structural elements of various technical units. Such an optimization entails a reduction in the total weight of the structures while maintaining operational properties and as a result increasing the efficiency of the end devices. As an example, we can consider bionic (topologically optimized) structures designed taking into account the results of the finite element analysis of the product in question state during operation. At the design stage all non-target load bearing zones are removed from the product body. The geometric complexity of such products does not allow them to be manufactured using traditional methods [6]. Research in the above-mentioned areas allows us to expand the boundaries of the selective laser melting technology application in various fields of the industrial sector.

Search for new materials applicable to additive manufacturing and development of technologies for the production of parts from these materials are the driving force for future development of additive technologies $[7,8]$. An important role in improving the production process using additive technologies is the formation of a special structure and properties in manufactured products. This is achieved due to special crystallization conditions, the creation of which is possible directly during the manufacturing process [8]. The aim of this work 
was to study the effect of the parameters of selective laser melting at a high temperature of heating the working zone on the properties of the formed material.

\section{EXPERIMENTAL METHODS}

The powder of heat-resistant nickel alloy used to obtain products by directional crystallization was used in this work. For research, nickel-based non-weldable alloy was chosen. This alloy is a common Russian secondgeneration heat-resistant alloy, used for the manufacture of turbine blades. In this work, we used a powder obtained by plasma atomization of a rotating electrode. This alloy is used to produce turbine blades with a single-crystal structure for aircraft gas turbine engines using directional crystallization. Due to the significant content of intermetallic compounds in the phase composition of the alloy and the high rates of local heating and cooling, cracking occurs in the material during selective laser melting. To avoid this, it is necessary to use the heating of the working area to reduce temperature gradients and reduce the number of cracks.

Table 1 Chemical composition of nickel-based alloy (wt\%)

\begin{tabular}{ccccccccccc}
\hline $\mathbf{N i}$ & $\mathbf{C r}$ & $\mathbf{A l}$ & $\mathbf{M o}$ & $\mathbf{W}$ & $\mathbf{C o}$ & $\mathbf{R e}$ & $\mathbf{T a}$ & $\mathbf{N b}$ & $\mathbf{C}$ & $\mathbf{B}$ \\
\hline Balance & 4.9 & 5.9 & 1.1 & 8.4 & 9.0 & 1.93 & 4.1 & 1.6 & 0.12 & 0.01 \\
\hline
\end{tabular}

Alloy is a three-phase system consisting of a nickel-based y-solid solution with an FCC crystal lattice, dispersion precipitates of the reinforcing $\mathrm{Y}^{\prime}$-phase based on the $\mathrm{Ni}_{3} \mathrm{Al}$ intermetallic and $\mathrm{MC}$ type carbides.

Rectangular specimens with dimensions of $10 \times 10 \times 30 \mathrm{~mm}$ were made from Nickel alloy powder (the chemical composition is given in Table 1) using Aconity3D MIDI selective laser melting machine (Aconity3D GmbH, Germany). The machine is equipped with laser source with variable focal spot diameter with Gauss power distribution and a maximum power 1000 watts. Moreover, machine is equipped with a module to enable operation with platform preheating up to $1200^{\circ} \mathrm{C}$.

$E=P /(S \cdot H \cdot L),\left(\mathrm{J} / \mathrm{mm}^{3}\right)$

Parameters of Selective laser melting (SLM) process differ in the value of the volumetric energy density $(E)$ (Eq. (1)) and in the time of the laser beam movement. The $E$ ranged from 60 to $120 \mathrm{~J} / \mathrm{mm}^{3}$. Laser power $(P)$ and scanning speed $(S)$ were used as changed factors inside each group. Hatch distance $(H)$ was set to 100 $\mu \mathrm{m}$ and layer thickness $(L)$ was set to $50 \mu \mathrm{m}$ (Table 2).

Table 2 Parameters of SLM process

\begin{tabular}{cccc}
\hline Specimens & $\boldsymbol{P}(\mathrm{W})$ & $\boldsymbol{S}(\mathrm{mm} / \mathrm{s})$ & $\boldsymbol{E}\left(\mathrm{J} / \mathrm{mm}^{3}\right)$ \\
\hline 1 & 300 & 1000 & 60 \\
2 & 600 & 2000 & 60 \\
3 & 450 & 1000 & 90 \\
4 & 900 & 2000 & 90 \\
5 & 450 & 750 & 120 \\
6 & 900 & 1200 & 120 \\
\hline
\end{tabular}

The chemical composition and microstructure of the specimens were analyzed on a Carl Zeiss Supra 55VP scanning electron microscope. Optical microstructure of the samples after SLM was examined on a Leica DMI 5000 light optical microscope. 


\section{RESULTS AND DISCUSSION}

The particle size distribution of the powder is in the range: $d_{10}=28.6 \mu \mathrm{m} ; d_{90}=92.3 \mu \mathrm{m}$, with an average value $d_{50}=55.8 \mu \mathrm{m}$. The powder has a particle shape close to ideal spheres, with a small number of surface defects.

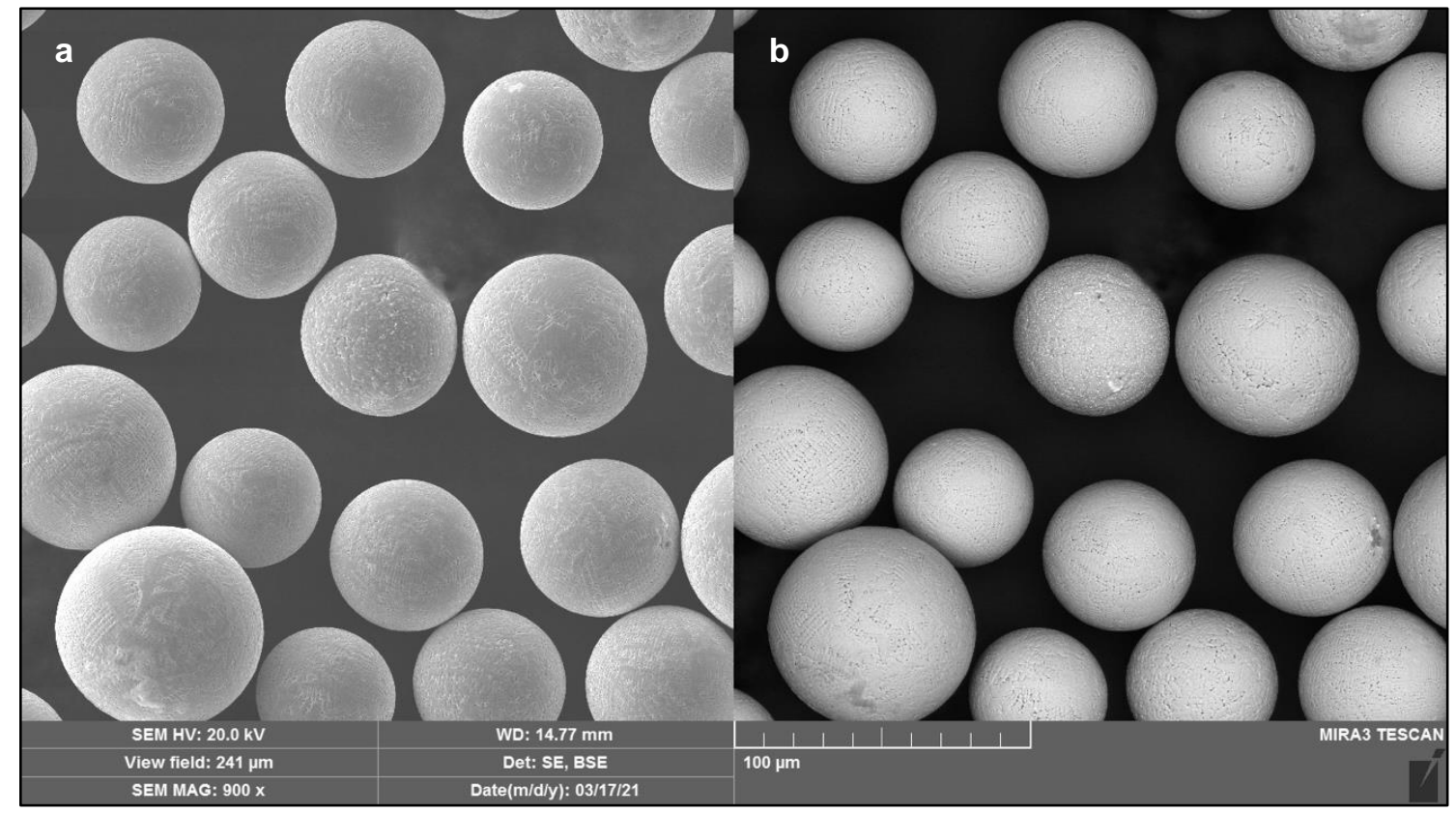

Figure 1 Particles of powder of non-weldable nickel-based superalloy. The type of detector used in survey SE (a), BSE (b)

The microstructure of the samples consists of cuboid $\gamma^{\prime}$-phase particles formed on the basis of the intermetallic compound $\mathrm{Ni}_{3} \mathrm{Al}$ distributed inside a $\gamma$ matrix of $\mathrm{Ni}(\mathrm{Al})$. The average $\gamma^{\prime}$ - phase particles size was $0.15-0.2 \mu \mathrm{m}$. Analysis of zones microstructure equally distant from the bottom of samples did not show dependence the size of the $\gamma^{\prime}$-phase particles on the parameters of the SLM process (Figures $2 \mathbf{a}, \mathbf{b}$ ). However, a decrease in the $\gamma^{\prime}$-phase particle size along the growing direction was found (Figure $3 \mathbf{a}$ ).

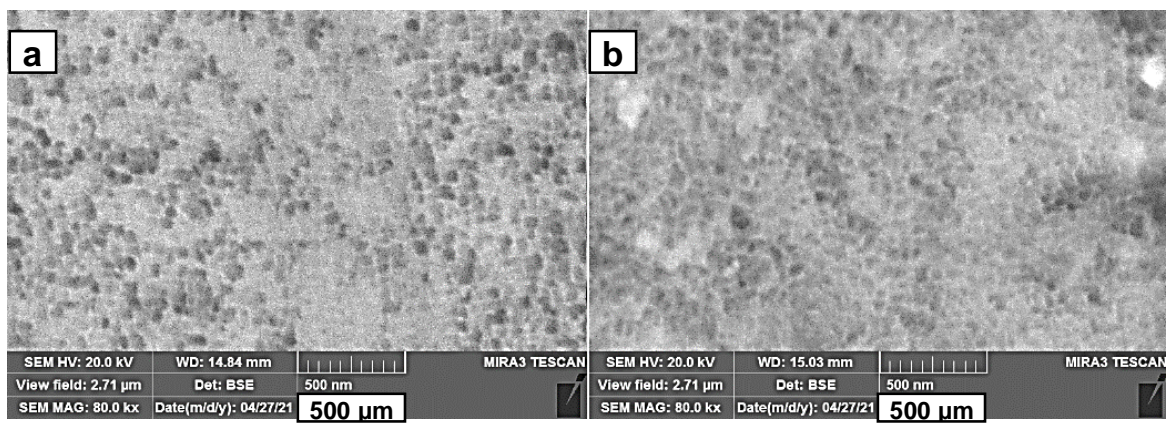

Figure 2 SEM images of the SLM $\gamma / \gamma^{\prime}$ microstructure at the top of specimens 1 (a), 6 (b)

In the underside of the samples, $\gamma^{\prime}$ - phase particles having a long, elongated shape, with traces of non-closed boundaries-solid solution are observed. This form may indicate a coagulation with a change in the morphology of the $\gamma^{\prime}$-phase particles. During the production of the samples, the lower layers were exposed to the heating temperature of the working platform for the longest time $\left(>1000{ }^{\circ} \mathrm{C}\right)$. Thus, the initial stage of raft structure formation can occur in the lower layers of the samples. Such a structure is usually formed in samples of heatresistant nickel-based superalloy under high-temperature creep (Figure 2 b). 
We must emphasize that plastic deformation in the creep process occurs either by sliding dislocations in the matrix channels and bending the $\gamma^{\prime}$-phase particles or by cutting the particles with dislocations to form defects. The formation of a raft structure eliminates the possibility of metal deformation by these mechanisms and leads to the implementation of more complex mechanisms for the movement of screw dislocations. This mechanism requires high energy input if the ratio of the plates length to their width is $>1$. Thus, a more energy-efficient mechanism would be to cut the plates with a pair of dislocations, what is the cause of embrittlement of the lower layers of the sample.

Despite the initial stage of combining the $\gamma^{\prime}$-phase particles into the raft structure plates, the production of the turbine blade will take much longer. Therefore, the lower layers will stay longer under conditions of hightemperature creep which can lead to the formation of a full-fledged raft structure in the lower layers.

The principle of layer-by-layer products manufacturing which is the basis of SLM technology leads to the limitations to preheating temperature values and manufacturing time of parts for the manufacture of singlecrystal gas turbine blades.

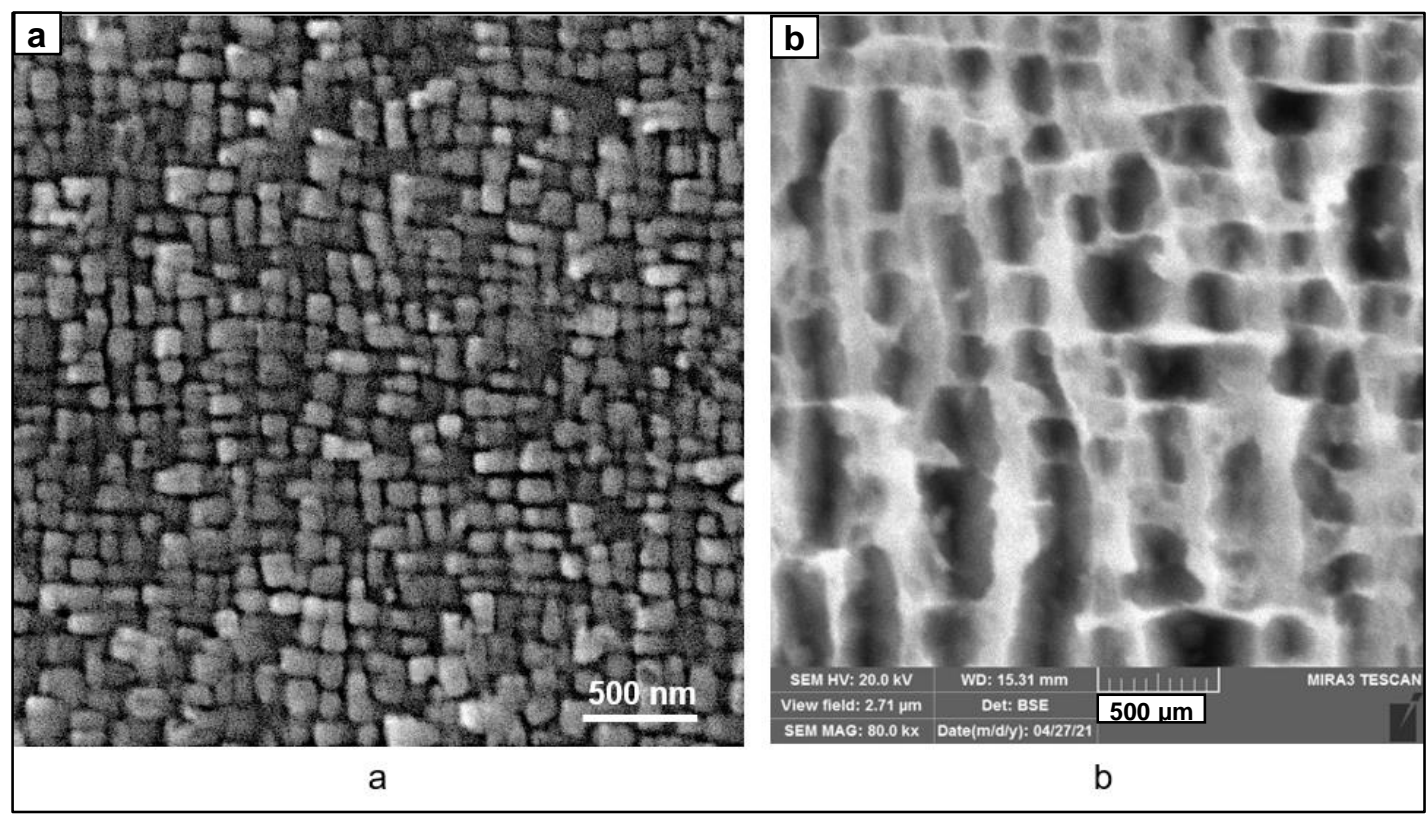

Figure 3 BSE images of the SLM $\gamma / \gamma^{\prime}$ microstructure at the top (a) and bottom (b) of specimen 6

In the process of manufacturing parts using high heating of the working platform, it is necessary to limit the heating temperature of the platform not higher than the working temperatures for the selected alloy.

\section{CONCLUSION}

In this paper, samples were made using 6 parameter sets (Table 2) to study the effect of SLM process parameters on the $\gamma / \gamma^{\prime}$ microstructure. For a comparative evaluation of the microstructure of the obtained samples, the size and shape of the $\gamma^{\prime}$ - phase particles were determined. Based on the data obtained, we can conclude that the scanning parameters do not affect the microstructure. However, during the study a regular change in the microstructure in the lower layers of all the samples was revealed. In the lower layers the initial stage of the cuboid structure $\gamma^{\prime}$-phase particles transition to the raft structure occurs. This transition occurs under the influence of the high heating temperature of the working platform $\left(>1000{ }^{\circ} \mathrm{C}\right)$, as well as under the influence of internal stresses that occur in the samples during crystallization during the SLM process. 


\section{ACKNOWLEDGEMENTS}

\section{This research was supported by Russian Science Foundation grant (project No 19-79-30002).}

\section{REFERENCES}

[1] CHAUVET, E. et al. Producing Ni-base superalloys single crystal by selective electron beam melting. Scripta Materialia. 2018, vol. 152, pp. 15-19.

[2] RAMSPERGER, M. et al. Selective electron beam melting of the single crystalline nickel-base superalloy CMSX-4 from columnar grains to a single crystal. In: Superalloys 2016: Proceedings of the $13^{\text {th }}$ International Symposium of Superalloys. 2016, January, pp. 341-349.

[3] GONCHAROV, I.S. et al. Synthesis of Nb-based powder alloy by mechanical alloying and plasma spheroidization processes for additive manufacturing. Materials Letters. 2019, vol. 245, pp. 188-191.

[4] XIONG, W. et al. Effect of selective laser melting parameters on morphology, microstructure, densification and mechanical properties of supersaturated silver alloy. Materials \& Design. 2019, vol. 170, p. 107697.

[5] POPOVICH, V.A., BORISOV, E.V., SUFIYAROV, V.S. et al. Tailoring the properties in functionally graded alloy Inconel 718 using additive technologies. Met Sci Heat Treat. 2019, vol. 60, pp. 701-709.

[6] GASSER, A. et al. Laser additive manufacturing: Laser metal deposition (LMD) and selective laser melting (SLM) in turbo-engine applications. Laser Technik Journal. [online]. 2010, pp. 58-63. Available from: https://doi.org/10.1002/latj.201090029.

[7] RAZUMOV, N.G. et al. Morphology of high-strength heat-resistant steel powder for machines for additive production from shavings. Metal Science and Heat Treatment. 2019, vol. 60, no. 11-12, pp. 710-714.

[8] XU, JIANJUN et al. The initiation and propagation mechanism of the overlapping zone cracking during laser solid forming of IN-738LC superalloy. Journal of Alloys and Compounds. 2018, vol. 749, pp. 859-870.

[9] BORISOV, E.V. et al. Selective laser melting of Inconel 718 under high laser power. Materials Today: Proceedings. 2020, vol. 30, pp. 784-788. 